\title{
PENGARUH KUALITAS LAYANAN DAN CITRA SEKOLAH TERHADAP LOYALITAS STAKEHOLDER SEKOLAH ISLAM AL-FALAH KOTA JAMBI
}

\author{
Kuswanto $^{1}$, May Maemunah ${ }^{1}$, Ranggi Dwi Putra ${ }^{1}$ \\ ${ }^{1}$ Program Studi Pendidikan Ekonomi, Fakultas Keguruan dan Ilmu Pendidikan, Universitas \\ Jambi \\ e-mail: kuswantomsi14@gmail.com
}

\begin{abstract}
Abstrak
Penelitian ini bertujuan untuk mengetahui pengaruh kualitas layanan dan citra sekolah terhadap loyalitas stakeholder Sekolah Islam Al-Falah Kota Jambi. Jenis Penelitian deskriptif kuantitatif. Subjek penelitian adalah stakeholder Sekolah Islam Al-Falah Kota Jambi, yaitu orang tua siswa, sebanyak 58 orang yang dipilih secara proporsional dari setiap kelas. Data dikumpulkan dengan menggunakan metode wawancara dan observasi. Data dianalisis secara deskriptif dan kuantitatif menggunakan regresi berganda. Hasil analisis menunjukkan bahwa sebagian besar $(56,9 \%)$ stakeholder memiliki persepsi yang tinggi tentang kualitas layanan yang diberikan oleh Sekolah Islam Al-Falah Kota Jambi. Terdapat 51,7 persen Stakeholder menilai Citra Sekolah Islam Al-Falah Kota Jambi Sangat Baik dan terdapat 56,9 persen Stakeholder memiliki loyalitas tinggi terhadap Sekolah Islam Al-Falah Kota Jambi. Hasil uji statistic menunjukan kemampuan model dalam memprediksikan pengaruh persepsi stakeholder dan citra sekolah terhadap loyalitas sebesar 53 persen. Kualitas layanan berpengaruh positif dan signifikan terhadap loyalitas stakeholder yang ditunjukan oleh koefisien $t_{\text {hit }} 2,783>t_{t a b}, 1,67$. Citra sekolah berpengaruh positif dan signifikan terhadap loyalitas stakeholder yang ditunjukan oleh koefisien thit 2,518> 1,67 tab. Secara simultan, kualitas layanan dan citra sekolah berpengaruh positif dan signifikan terhadap loyalitas yang ditunjukan oleh koefisien $F_{h i t} 33,033>F_{\text {tab }} 3,16$. Untuk meningkatkan loyalitas stakeholder, Sekolah Islam Al-falah Kota Jambi harus meningkatkan citra sekolah dan kualitas layanan kepada stakeholder.
\end{abstract}

Kata Kunci: Kualitas Layanan, Citra Sekolah, Loyalitas Stakeholder.

\section{PENDAHULUAN}

Sekolah Islam terpadu merupakan model baru lembaga pendidikan di Indonesia. Menurut Suyatno (2015:2), kemunculan sekolah Islam Terpadu ini dilatarbelakangi oleh adanya ketidakpuasan sebagian besar aktor gerakan Islam di Indonesia terhadap perkembangan sistem pendidikan nasional. Adanya dikotomi ilmu antara ilmu agama dan umum di Sekolah telah menyebabkan lembaga pendidikan di Indonesia tidak mampu menciptakan lulusan yang berkepribadian utuh. Dikotomi ilmu akhirnya melembaga dalam bentuk dualisme sistem pendidikan Nasional, sekolah agama yang berada dibawah Kementrian Agama (MI, MTs, MA, hingga Perguruan Tinggi Agama Islam) dan sekolah umum yang berada di bawah Kementrian Pendidikan dan Kebudayaan (TK, SD, SMP, SMA, hingga Perguruan Tinggi Umum).

Menurut Wijaya (dalam Rohmitriasih dan Soetopo, 2015), aktivitas pemasaran jasa pendidikan yang dilakukan sekolah dapat mengubah penilaian masyarakat terhadap kualitas 
sekolah dalam jangka panjang dan merupakan cara untuk membangun citra sekolah secara keseluruhan. Kemampuan sekolah di dalam membuat strategi pemasaran akan menentukan eksistensi sekolah tersebut sebagai penyelenggara pendidikan.

Salah satu tolak ukur keberhasilan sekolah dalam menyelenggarakan pendidikan ditentukan oleh tingkat kepuasan pengguna jasa pendidikan tersebut, baik siswa sebagai peserta didik maupun keluarga dan masyarakan sebagai pengguna lulusan. Kepuasan yang dirasakan oleh stakeholder merupakan wujud dari layanan yang berkualitas yang selanjutnya akan membangun loyalitas terhadap sekolah. Sebagaimana dijelaskan oleh Boulding, Staelin, dan Zeithaml (1993), Bloemer, Ruyter dan Peeters (1998) (dalam Mardalis, 2005), bahwa terjadinya loyalitas karena adanya kepuasan/ ketidakpuasan dengan produk yang diterima yang berakumulasi secara terus menerus. Loyalitas stakeholder terhadap sekolah ditunjukan dengan komitmennya untuk tetap memilih sekolah sebagai penyelenggara pendidikan. Penelitian yang dilakukan oleh Putra (2017), menjelaskan bahwa kepuasan memediasi pengaruh kualitas layanan terhadap loyalitas pelanggan.

Sekolah Islam Al-Falah merupakan salah satu sekolah Islam terpadu yang ada di Kota Jambi yang menyelenggarakan pendidikan dari tingkat SD, SMP dan SMA. Citra Sekolah Islam terpadu merupakan model lembaga pendidikan yang dipandang mampu memenuhi kebutuhan pendidikan intelektual dan spiritual. Persepsi stakeholder terhadap citra sekolah Islam terpadu menjadi alasan tersendiri dalam memilih sekolah sebagai penyelenggara pendidikan. Sebagaimana penelitian yang dilakukan oleh Ruzikna dan Anggraini (2015), bahwa persepsi terhadap merek berpengaruh positif dan signifikan terhadap loyalitas pelanggan.

Loyalitas stakeholder terhadap sekolah Islam Al-Falah terlihat pada keputusannya memilih sekolah tersebut sebagai penyelenggara pendidikan secara berkesinambungan, sebagaimana terlihat pada tabel 1 .

Tabel 1.

Jumlah Lulusan yang Mendaftar Ulang pada Sekolah Islam Al-Falah

\begin{tabular}{ccccc}
\hline Tahun Ajaran & $\begin{array}{c}\text { Jenjang } \\
\text { Pendidikan }\end{array}$ & Jumlah Peserta didik & $\begin{array}{c}\text { Jumlah } \\
\text { Lulusan }\end{array}$ & $\begin{array}{c}\text { Prosentase } \\
\text { Mendaftar } \\
\text { Ulang (\%) }\end{array}$ \\
\hline $2017 / 2018$ & SD & 1192 & 173 & 13 \\
$2017 / 2018$ & SMP & 413 & 146 & 23 \\
$2017 / 2018$ & SMA & 432 & 126 & - \\
\hline
\end{tabular}

Sumber: Sekolah Islam Al-Falah Kota Jambi

Pada Tabel 1, dari 173 siswa SD yang lulus terdapat 13 persen (23) siswa yang mendaftar pada jenjang pendidikan menengah pertama (SMP) dan dari 146 siswa yang lulus SMP terdapat 23 persen (33) siswa yang melanjutkan pendidikan SMA pada sekolah tersebut. Rendahnya re-regristasi tersebut mengindikasikan rendahnya loyalitas stakeholder pada sekolah Islam Al-falah. Menurut Mardelis (2015), yang menyebabkan tinggi rendahnya loyalitas pelanggan adalah 1) kepuasan, 2) kualitas jasa, 3) citra, dan 4) rintangan untuk berpindah.

Berdasarkan latarbelakang di atas perlu dilakukan penelitian untuk mengkaji bagaimana pengaruh kualitas layanan dan citra sekolah terhadap loyalitas stakeholder Sekolah Islam AlFalah Kota Jambi.

\section{METODE}

Penelitian ini merupakan penelitian desktiptif kuantitatif, yaitu berusaha untuk mendeskripsikan fenomena-fenomena variable-variabel yang diteliti dan menganalisis tingkat 
pengaruh variable bebas terhadap variable terikat (Sukmadinata, 2015). Variabel bebas terdiri dari kualitas layanan dan persepsi terhadap citra sekolah. Kualitas layanan diukur berdasarkan indicator menurut Mahmud (2012:62), yaitu: 1) kemampuan (ability), 2) sikap (attitude), 3) perhatian (attention), 4) tindakan (action), 5) panampilan (appearance), 6) tanggung jawab (accountability). Persepsi citra sekolah diukur berdasarkan indicator menurut Pina et al, (2010:7), yaitu 1) persepsi, 2) reputasi, dan 3) sikap. Variabel terikat adalah loyalitas stakeholder yang diukur berdasarkan indicator menurut Tjiptono (dalam Rahmayanty, 2014:14), yaitu: 1) pembelian ulang, 2) kebiasaan mengkonsumsi merek, 3) selalu menyukai merek, 4) tetap memilih merek, 5) meyakini sebagai merek terbaik, 6) merekomendasikan kepada orang lain.

Penelitian ini dilakukan di SMP Islam Al-Falah Kota Jambi pada kelas 9 semester ganjil tahun ajaran 2017/2018. Subjek penelitian merupakan para pengguna jasa pendidikan, yaitu orang tua siswa yang dipilih secara proporsional dari setiap kelas sebanyak 58 dari 136 orang tua siswa yang dihitung dengan menggunakan rumus sebagaimana dikembangkan oleh Supriyadi (2014:18) berikut ini:

$$
\begin{aligned}
& n=\frac{N}{1+N e^{2}} \ldots \ldots \ldots \ldots \ldots . . . \\
& n=\frac{136}{1+136 \times 0.1^{2}}=58
\end{aligned}
$$

Tabel 2

Jumlah Populasi dan Sampel

\begin{tabular}{lrr}
\hline Kelas & Populasi & Sampel \\
\hline IXa & 34 & 14 \\
IXb & 34 & 14 \\
IXc & 35 & 15 \\
IXd & 33 & 14 \\
\hline Total & 136 & 58 \\
\hline
\end{tabular}

Sumber: TU SMP Islam Al-Falah Kota Jambi 2017 (diolah)

Data dianalisis menggunakan metode Ordinary Last Square (OLS) dalam bentuk regresi berganda (Winarno, 2009), sebagaimana berikut:

$$
Y=\beta_{0}+\beta_{1} X_{1}+\beta_{2} X_{2}+\varepsilon
$$

Dimana:

Y : loyalitas stakeholder

$\mathrm{X}_{1} \quad$ : kualitas layanan

$\mathrm{X}_{2} \quad$ : persepsi citra sekolah

$\beta_{0} \quad$ : konstanta

$\beta_{1,2} \quad$ : koefisien

$\varepsilon \quad$ : residual 


\section{HASIL DAN PEMBAHASAN}

\section{Hasil Penelitian}

Pengukuran terhadap variabel yang diteliti menggunakan instrument dengan skala likert 1 - 5 yang disusun berdasarkan indicator masing-masing variabel yang telah ditentukan. Dari data yang diperoleh dapat dideskriptifkan variabel-variabel yang diteliti tersebut.

\section{Deskripsi Kualitas Layanan Sekolah Islam Al-Falah Kota Jambi}

Kualitas layanan sekolah Islam Al-Falah Kota Jambi merupakan bentuk layanan yang diberikan kepada stakeholder dalam menwujudkan pendidikan yang berkualitas. Kualitas layanan dirasakan oleh stakeholder apabila memberikan kepuasan atas layanan yang diberikan. Gambaran kualitas layanan sekolah Islam Al-Falah Kota Jambi dijelaskan pada tabel 3 berikut ini:

Tabel 3. Deskripsi Kualitas Layanan Sekolah Islam Al-Falah Kota Jambi

\begin{tabular}{ccccc}
\hline No & Interval & Kategori & F & Persentase \% \\
\hline 1 & $57-70$ & Sangat Baik & 30 & 51,7 \\
2 & $43-56$ & Baik & 28 & 48,3 \\
3 & $29-42$ & Sedang & 0 & $0 \%$ \\
4 & $15-28$ & Tidak Baik & 0 & $0 \%$ \\
5 & $0-14$ & Sangat Tidak Baik & 0 & $0 \%$ \\
\hline & Jumlah & & 58 & 100 \\
\hline
\end{tabular}

Sumber: data primer 2017 (diolah)

Berdasarkan Tabel 3, sebagaian besar (51,7\%) Stakeholder menilai kualitas layanan sekolah Islam Al-Falah Kota Jambi sangat baik, dan terdapat 48,3 persen stakeholder yang menilai kualitas layanan sekolah Islam Al-Falah Kota Jambi dalam kategori baik.

\section{Deskriptif Persepsi Citra Sekolah Islam Al-Falah Kota Jambi}

Tabel 4. Persepsi Staekholder tentang Citra Sekolah Islam Al-Falah Kota Jambi

\begin{tabular}{ccccc}
\hline No & Interval & Kategori & F & Persentase \% \\
\hline 1 & $57-70$ & Sangat Baik & 30 & $51,7 \%$ \\
2 & $43-56$ & Baik & 28 & $48,3 \%$ \\
3 & $29-42$ & Sedang & 0 & $0 \%$ \\
4 & $15-28$ & Tidak Baik & 0 & $0 \%$ \\
5 & $0-14$ & Sangat Tidak Baik & 0 & $0 \%$ \\
\hline & Jumlah & & 58 & $100 \%$ \\
\hline
\end{tabular}

Sumber: data primer 2017 (diolah)

Berdasarkan Tabel 4, sebagian besar (30\%) Stakeholder meiliki persepsi yang sangat baik terhadap citra sekolah Islam Al-Falah Kota Jambi, dan terdapat 28 persen Stakeholder yang memiliki persepsi dengn kategori baik terhadap citra sekolah Islam Al-Falah Kota Jambi. 


\section{Deskriptif Loyalitas Staekholder Sekolah Islam Al-Falah Kota Jambi}

Tabel 5. Loyalitas Staekholder terhadap Sekolah Islam Al-Falah Kota Jambi

\begin{tabular}{ccccc}
\hline No & Interval & Kategori & F & Persentase \% \\
\hline 1 & $93-115$ & Sangat Tinggi & 25 & 43,1 \\
2 & $70-92$ & Tinggi & 33 & 56,9 \\
3 & $47-69$ & Sedang & 0 & 0 \\
4 & $24-46$ & Rendah & 0 & 0 \\
5 & $0-23$ & Sangat Rendah & 0 & 0 \\
\hline & Jumlah & & 58 & 100 \\
\hline
\end{tabular}

Sumber: data primer 2017 (diolah)

Berdasarkan Tabel 5, sebagian besar (33\%) Stakeholder memiliki loyalitas yang tinggi terhadap sekolah Islam Al-Falah Kota Jambi dan terdapat 25 persen Stakeholder memiliki loyalitas yang sangat tinggi.

\section{Hasil Analisis Regresi}

Analisis regresi dilakukan untuk mengatahui pengaruh kualitas layanan dan citra sekolah terhadap loyalitas Stakeholder sekolah Islam Al-Falah Kota Jambi, baik secara parsial maupun secara silmultan, sebagaimana ditunjukan pada Tabel 6 .

Tabel 6. Hasil Analisis Regresi

\begin{tabular}{|c|c|c|c|c|c|c|c|c|}
\hline \multirow{2}{*}{\multicolumn{2}{|c|}{ Model }} & \multicolumn{2}{|c|}{$\begin{array}{c}\text { Unstandardized } \\
\text { Coefficients }\end{array}$} & \multirow{2}{*}{$\begin{array}{l}\text { Standardized } \\
\text { Coefficients } \\
\text { Beta }\end{array}$} & \multirow[t]{2}{*}{$\mathrm{t}$} & \multirow[t]{2}{*}{ Sig. } & \multicolumn{2}{|c|}{$\begin{array}{c}\text { Collinearity } \\
\text { Statistics }\end{array}$} \\
\hline & & $\mathrm{B}$ & $\begin{array}{l}\text { Std. } \\
\text { Error }\end{array}$ & & & & Tolerance & VIF \\
\hline & (Constant) & 19,36 & 9,05 & & 2,14 & 0,037 & & \\
\hline \multirow[t]{2}{*}{1} & Kualitas_Layanan & 0,41 & 0,15 & 0,41 & 2,78 & 0,007 & 0,380 & 2,631 \\
\hline & Citra_Sekolah & 0,63 & 0,25 & 0,37 & 2,52 & 0,015 & 0,380 & 2,631 \\
\hline
\end{tabular}

a. Dependent Variable: Loyalitas_Stakeholder

Berdasarkan tabel 6, besaran kostanta yang dihasilkan 19,36 menjelaskan bahwa apabila tidak terdapat penilaian stakeholder tentang kualitas layanan dan citra sekolah Islam Al-Falah Kota Jambi, maka loyalitas Stakelolder sebesar 19,36 satuan. Koefisien variable kualitas layanan bernilai positif sebesar 0,41, artinya apabila penilaian stakeholder tentang kualitas layanan meningkat sebesar 1 satuan maka loyalitasnya terhadap sekolah Islam AlFalah Kota Jambi meningkat sebesar 0,41 satuan. Pengaruh variable kualitas layanan terhadap loyalitas Stakeholder sekolah Islam Al-Falah Kota Jambi secara statistic signifikan yang ditunjukan dengan nilai $t_{h i t}$ sebesar 2,78 lebih besar dibandingkan dengan nilai $t_{\text {tab }}$ $(\alpha=5 \%, \mathrm{df}=57) 2,00$.

Koefisien variable citra sekolah bernilai positif sebesar 0,63 , artinya apabila persepsi stakeholder tentang citra sekolah meningkat sebesar 1 satuan akan meningkatkan loyalitasnya terhadap sekolah Islam Al-Falah Kota Jambi sebesar 0,63 satuan. Pengaruh tersebut secara statistic signifikan yang ditunjukan dengan nilai nilai $t_{\text {hit }}$ sebesar 2,52 lebih besar 
dibandingkan dengan nilai $t_{\text {tab }}(\alpha=5 \%, d f=57)$ 2,00. Secara matematik pengaruh variable bebas $\left(\mathrm{X}_{1}\right.$ dan $\left.\mathrm{X}_{2}\right)$ terhadap terikan $(\mathrm{Y})$ tersebut dapat dijelaskan pada persamaan berikut ini: $Y=19,36+0,41 X_{1}+0,63 X_{2}$

Model di atas dapat digunakan untuk memprediksikan tingkat loyalitas Stakeholder yang disebabkan oleh tingkat persepsi Stakeholder tentang kualitas layanan dan citra sekolah Islam Al-Falah Kota Jambi. Berdasarkan tabel 7 nilai Adjusted R Square sebesar 0,53, menjelaskan bahwa kemampuan model dalam memprediksikan pengaruh variable kualitas layanan dan citra sekolah terhadap loyalitas Stakeholder sebesar 53 persen, dan selebihnya $(47 \%)$ ditentukan oleh variable lain yang tidak diperhitungkan di dalam model.

\section{Tabel 7. Model Summary}

\begin{tabular}{lrrrrr}
\hline Model & R & R Square & \multicolumn{1}{c}{$\begin{array}{c}\text { Adjusted R } \\
\text { Square }\end{array}$} & $\begin{array}{c}\text { Std. Error of the } \\
\text { Estimate }\end{array}$ & Durbin-Watson \\
\hline 1 & $0,74^{\mathrm{a}}$ & 0.55 & 0.53 & 8,13 & 1,61 \\
\hline
\end{tabular}

a. Predictors: (Constant), Citra_Sekolah, Kualitas_Layanan

b. Dependent Variable: Loyalitas_Stakeholder

Secara simultan, variable kualitas layanan dan citra sekolah berpengaruh signifikan terhadap loyalitas Stakeholder sekolah Islam Al-Falah Kota Jambi sebagaimana ditunjukan dengan nilai $F_{\text {hit }}$ pada Tebel 8, yaitu sebesar 33,03 lebih besar dibandingkan dengan nilai $F_{\text {tab }}$ $(\alpha=5 \%, \mathrm{df}=56) 3,16$.

Tabel 8. ANOVA

\begin{tabular}{rlrrrrr}
\hline Model & & Sum of Squares & df & Mean Square & F & Sig. \\
\hline \multirow{2}{*}{1} & Regression & 4361.374 & 2 & 2180.687 & 33.033 & $.000^{\mathrm{b}}$ \\
& Residual & 3630.902 & 55 & 66.016 & & \\
& Total & 7992.276 & 57 & & & \\
\hline
\end{tabular}

a. Dependent Variable: Loyalitas_Stakeholder

b. Predictors: (Constant), Citra_Sekolah, Kualitas_Layanan

\section{Pembahasan}

Pelayanan pendidikan merupakan bentuk konsekunsi dari penyelenggaraan pendidikan yang diberikan oleh sekolah kepada Stakeholder. Sebagian besar Stakeholder menilai kualitas layanan Sekolah Islam Al-Falah Kota Jambi dalam menyelenggarakan pendidikan sangat baik. Penilaian Stakeholder terhadap kualitas layanan sekolah diukur dari: 1) kemampuan (ability), 2) sikap (attitude), 3) perhatian (attention), 4) tindakan (action), 5) panampilan (appearance), 6) tanggung jawab (accountability) dalam memberikan layanan kepada Stakeholder.

Layanan sekolah yang berkualitas akan memberikan kepuasan kapada Stakeholder yang ditunjukan dalam bentuk loyalitas yang tinggi kepada sekolah Islam Al-Falah Kota Jambi. Loyalitas Stakeholder kepada sekolah terlihat dari kikapnya dalam bentuk: 1) komitmennya membayar biaya-biaya pendidikan yang telah ditetapkan oleh sekolah dan memilih kembali Sekolah Islam Al-Falah sebagai tempat pendidikan bagi anaknya pada jenjang yang lebih tinggi; 2) selalu menyekolahkan anak di sekolah Islam Al-falah; 3) menyukai Sekolah Islam 
Al-Falah sebagai lembaga pendidikan; 4) tetap memilih sekolah Islam Al-falah meskipun dihadapkan dengan pilihan sekolah lain; 5) meyakini sebagai sekolah terbaik, 6) merekomendasikan kepada orang lain untuk menyekolahkan anaknya di sekolah Islam Alfalah Kota Jambi.

Hasil analisis regresi menjelaskan bahwa semakin tinggi kualitas layanan Sekolah, maka akan semakin meningkatkan loyalitas Stakeholder kepada sekolah Islam Al-Falah Kota Jambi. Loyalitas Stakeholder terbentuk dari kepuasan yang diperoleh atas layanan yang diberikan oleh sekolah Islam Al-Falah Kota Jambi. Dengan meningkatnya kualitas layanan yang diberikan oleh sekolah, kepuasan Stakeholder sebagai pengguna jasa pendidikan menjadi meningkat yang diwujudkan dalam bentuk loyalitasnya kepada sekolah Islam AlFalah. Dengan demikian, untuk meningkatkan loyalitas Stakeholder, sekolah Islam Al-Falah Kota Jambi harus menjaga dan meningkatkan kualitas layanan yang diberikan.

Selain kualitas layanan, loyalitas Stakeholder kepada sekolah Islam Al-Falah Kota Jambi juga ditentukan oleh citra sekolah. Hasil analisis deskriptif menjelaskan bahwa penilaian Stakeholder terhadap citra sekolah Islam Al-Falah Kota Jambi sangat baik. Stakeholder menilai bahwa sekolah Islam Al-Falah merupakan sekolah yang mampu memberikan kebutuhan belajar spiritual, intelektual dan social yang sangat baik. Disamping itu, sekolah Islam Al-falah juga dipandang memiliki reputasi yang tinggi. Sekolah Islam AlFalah juga dipandang sebagai sekolah yang konsisten di dalam menerapkan nilai-nilai Islam dalam system pendidikan.

Berdasarkan hasil analisis regresi, menjelaskan bahwa semakin baik penilaian Stakeholder terhadap citra sekolah akan semakin meningkatkan loyalitasnya kepada sekolah Islam Al-Falah Kota Jambi. Citra sekolah Islam merupakan cerminan karakteristik penyelenggaraan pendidikan Islam yang dipandang oleh Stakeholder mampu memenuhi kebutuhan belajar dari segi intelektual, spiritual dan social. Stakeholder meyakini peyelenggaraan sekolah Islam terpadu lebih efektif dalam membentuk karakter anak yang utuh dan seimbang antara rohani dan jasmani. Dengan adanya image yang baik tersebut, menjadikan Stakeholder semakin loyal terhadap sekolah Islam Al-Falah Kota Jambi.

Hasil analisis simultan variable kualitas layanan dan citra sekolah berpengaruh terhadap loyalitas Stakeholder kepada sekolah Islam Al-Falah Kota Jambi. Stakeholder menilai kualitas layanan sekolah dan menilai citra sekolah sangat baik sehingga loyalitasnya kepada sekolah Islam Al-Falah Kota Jambi menjadi sangat tinggi.

\section{PENUTUP}

Berdasarkan hasil penelitian dan pembahasan di atas dapat disimpulkan bahwa sebagian besar Stakeholder menilai kualitas layanan dan citra sekolah sekolah Islam Al-Falah Kota Jambi sangat sangat baik. Loyalitas Stakeholder terhadap sekolah sekolah Islam AlFalah Kota Jambi sangat tinggi. Semakin baik kualitas layanan dan citra sekolah, semakin meningkatkan loyalitas Stakeholder kepada sekolah sekolah sekolah Islam Al-Falah Kota Jambi. 
Berdasarkan hasil penelitian tersebut, sekolah sekolah Islam Al-Falah Kota Jambi harus mempertahankan dan meningkatkan kualitas layanan dan citra sekolah Islam agar loyalitas Stakeholder kepada sekolah semakin meningkat.

\section{DAFTAR PUSTAKA}

Soetopo, H. dan Rohmitriasih. 2015. Strategi Pemasaran Jasa Pendidikan Dalam Meningkatkan Loyalitas Pelanggan. Jurnal Manajemen Pendidikan. Vol. 24. No. 5 (Maret). pp. 402-407.

Mardalis, A. 2005. Meraih Loyalitas Pelanggan. Jurnal BENEFIT. Vol. 9, No. 2 (Desember). pp. 111-119.

Putra, H, A. dan Ngatno. 2017. Pengaruh Kualitas Pelayanan Terhadap Loyalitas Konsumen Melalui Kepuasan Konsumen Sebagai Variabel Intervening (Studi Kasus Pada Konsumen PT. Lontar Media Digital Printing Semarang). Diponegoro Journal Of Social And Political. hal. 1-8. http://ejournal-s1.undip.ac.id/index.php/

Ruzikna. dan Anggraini, F. 2015. Pengaruh Brand Image Terhadap Loyalitas Pelanggan Pada Koran Harian Riau Pos. Jurnal JOM FISIP. Vol. 3 No.1 (Februari). hal. 1-17.

Sukmadinata, S, N. 2015. Metode Penelitian Pendidikan. PT. Remaja Rosdakarya. Bandung.

Mahmud, A. 2012. Manajemen Mutu Perguruan Tinggi. Raja Grafindo Persada. Jakarta.

Rahmayanty, N. 2014. Manajemen Pelayanan Prima. Graha Ilmu. Yogyakarta.

Pina, J, M. Martinez, E. Chernatony, L. Drury, S. 2006. The effect of service brand extensions on corporate image: An empirical model, European Journal of Marketing, Vol. 40 Issue: 1/2, pp.174-197, https://doi.org/10.1108/03090560610637374

Supriyadi, E. 2014. SPSS+Amos. In Media. Jakarta

Winrno, W, W. 2009. Analisis Ekonometrika dan Statistika dengan Eviews. UPP STIM YKPN. Yogyakarta. 